ERRATUM

Peter Politzer · Jane S. Murray $\cdot$ Pat Lane $\cdot$

Monica C. Concha $\cdot$ Ping Jin $\cdot$ Zenaida Peralta-Inga

\title{
An unusual feature of end-substituted model carbon $(6,0)$ nanotubes
}

\section{J Mol Model (2005) 11: 258-264}

In the original article, the color portions of Figs. 6 and 7 were interchanged, so that each was with the wrong caption. The correct figures and captions are shown.

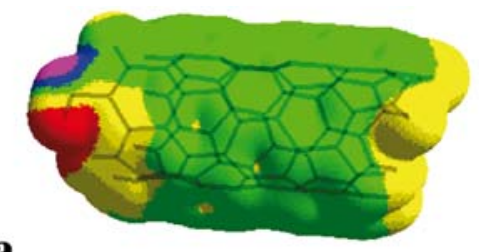

$\mathbf{a}$

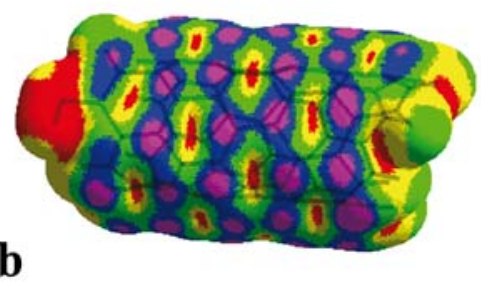

Fig. $6 \mathrm{HF} / \mathrm{STO}-5 \mathrm{G}$ electrostatic potential (a) and average local ionization energy (b) on outer surface of open $(6,1) \mathrm{C}_{68} \mathrm{H}_{13} \mathrm{OH}$. The hydroxyl group is at the left end of the tube. Color ranges are the same as in Fig. 5

The online version of the original article can be found at http://dx. doi.org/10.1007/s00894-005-0265-6

P. Politzer $(\bowtie) \cdot J$. S. Murray · P. Lane · M. C. Concha · P. Jin ·

Z. Peralta-Inga

Department of Chemistry, University of New Orleans,

New Orleans, LA 70148, USA

e-mail: ppolitze@uno.edu

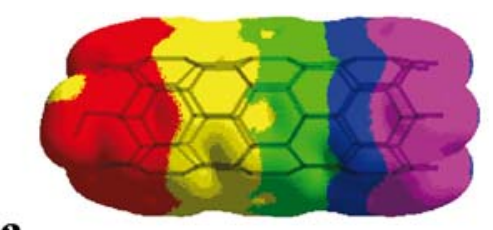

$\mathbf{a}$

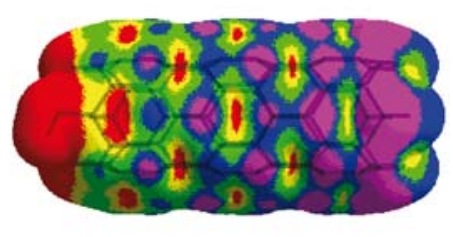

Fig. $7 \mathrm{HF} / \mathrm{STO}-5 \mathrm{G}$ electrostatic potential (a) and average local ionization energy (b) on outer surface of open $(6,0) \mathrm{C}_{72} \mathrm{H}_{11} \mathrm{OH}$. The hydroxyl group is at the left end of the tube. Color ranges are the same as in Fig. 5 